\title{
Overlaps and uncertainties of smoking-related idiopathic interstitial pneumonias
}

\author{
This article was published in the following Dove Press journal: \\ International Journal of COPD \\ I November 2017 \\ Number of times this article has been viewed
}

\author{
So Hyeon Bak ${ }^{1,2}$ \\ Ho Yun Lee \\ 'Department of Radiology and \\ Center for Imaging Science, Samsung \\ Medical Center, Sungkyunkwan \\ University School of Medicine, Seoul, \\ ${ }^{2}$ Department of Radiology, Kangwon \\ National University Hospital, \\ Chuncheon, Korea
}

\begin{abstract}
Smoking-related interstitial lung disease (ILD) consists of a heterogeneous group of disorders that are considered a distinct entity. The 2013 American Thoracic Society and European Respiratory Society recommendations classified respiratory bronchiolitis (RB)/RB-ILD and desquamative interstitial pneumonia (DIP) as smoking-related idiopathic interstitial pneumonias (IIPs). The overlapping histopathological and radiological patterns of smoking-related IIPs must be considered. Overlap patterns of smoking-related IIPs are not easily classified as a single disorder. The initial radiological manifestation and follow-up changes are heterogeneous, even when diagnosed pathologically as RB or DIP. Therefore, a clinical-radiological-pathological consensus is important in the diagnosis of smoking-related IIPs, and long-term evaluation is essential to monitor the morphological changes in these patients. In this article, we reviewed the clinical, radiological, and pathological findings, and also the changes in radiological manifestations of smoking-related IIPs over time.
\end{abstract}

Keywords: smoking, diagnosis, biopsy, computed tomography

\section{Introduction}

Tobacco smoke is a toxic and carcinogenic mixture composed of $>5,000$ types of chemicals that causes many pulmonary and systemic effects in human beings. ${ }^{1,2}$ Inhalation of the toxic particles associated with cigarette smoking and the subsequent immune response may lead to a variety of pathological manifestations. ${ }^{3}$ Cardiovascular disease, chronic obstructive pulmonary disease (COPD), and lung cancer are the most frequent causes of smoking-related deaths; however, many patients also suffer from smoking-related interstitial lung disease (ILD). ${ }^{2,4}$ Recently, smoking has also been implicated in the pathogenesis of ILDs, such as desquamative interstitial pneumonia (DIP), respiratory bronchiolitis (RB)/RB-ILD, Langerhans cell histiocytosis (LCH), and idiopathic pulmonary fibrosis (IPF). ${ }^{5}$ However, the relationship between cigarette smoking and ILD has not yet been established. ${ }^{1,6}$ Smoking-related ILD consists of a heterogeneous group of disorders that can overlap with one another or coexist with other sequelae of cigarette smoking, such as emphysema. ${ }^{3,4}$

In particular, RB/RB-ILD and DIP, which were classified as smoking-related idiopathic interstitial pneumonias (IIPs) in the revision of the 2013 American Thoracic Society/European Respiratory Society (ATS/ERS) IIP statement, represent a histological spectrum of macrophage accumulation depending on the extent and distribution of this accumulation. ${ }^{7-9} \mathrm{RB} / \mathrm{RB}-\mathrm{ILD}$ and DIP remain separately classified because of their differences in clinical entities, radiological manifestations and response to treatment. ${ }^{9}$ However, it is not surprising that the histopathological patterns and imaging findings may overlap between RB/RB-ILD and DIP; a prospective diagnosis can be difficult. ${ }^{3,4,10}$ 
Few studies have examined the early or long-term follow-up manifestations on chest computed tomography (CT) in patients with $\mathrm{RB} / \mathrm{RB}-\mathrm{ILD}$ or DIP. In this article, we reviewed the clinical, radiological, and pathological findings and also the changes in radiological manifestations over time of smoking-related IIPs.

\section{Smoking-related idiopathic interstitial pneumonias (IIPs) \\ RB and RB-ILD}

$\mathrm{RB}$ is a universal inflammatory reaction of the respiratory bronchioles that always occurs in current smokers and is known as smoker's bronchiolitis. ${ }^{9,11,12}$ RB associated with clusters of pigmented alveolar macrophages was first described in 1974. ${ }^{13}$ Exposure to cigarette smoke causes an increase in the number of alveolar macrophages that are created in an attempt to remove any inhaled particles and changes the macrophage phenotype to enhance resolution of inflammation and tissue remodeling. ${ }^{3,6,14,15}$ RB occurs because of increased macrophage numbers and is regarded as a normal physiological response to inhaled cigarette smoke. ${ }^{6,12}$ The prominent histological feature of RB is a bronchiolocentric accumulation of yellow-brown pigmented macrophages (smoker's macrophages) in the respiratory bronchioles and adjacent alveoli. ${ }^{8,12,16}$ Most patients with RB are asymptomatic, but a small proportion of smokers with RB develop clinical, physiological, and imaging features of ILD, which is termed RB-ILD. ${ }^{12,17}$ In 1987, Myers et al ${ }^{18}$ described six patients with clinical and radiological features of chronic ILD whose open lung biopsies showed RB and fibrosis that extended from the peribronchiolar regions into the adjacent alveolar septa. RB-ILD is a rare disorder characterized by dyspnea and cough and represents a pulmonary function abnormality encountered in heavy smokers in the third to sixth decades of life with a 30 pack-year history at the time of diagnosis. ${ }^{12}$ Pulmonary function tests (PFTs) reveal a mixed obstructive-restrictive defect with a mild to moderate decrease in the diffusing capacity of the lung for carbon monoxide (DLco). ${ }^{12,19,20}$ The severity of impairment of PFT is a feature that distinguishes RB-ILD from RB. ${ }^{8}$

In $\mathrm{RB} / \mathrm{RB}-\mathrm{ILD}$, the chest radiograph is usually normal and has a limited diagnostic value. ${ }^{21}$ Bronchial wall thickening and ground-glass opacity (GGO) are frequent on chest radiograph in patients with RB/RB-ILD. ${ }^{22}$ Given that macrophages are distributed in the respiratory bronchioles, centrilobular nodules are a computed tomographic feature associated with the bronchiolocentric histology of RB/RB-ILD., ${ }^{3,23}$ The most common CT findings of RB/RB-ILD are poorly defined centrilobular nodules with an upper zone distribution, patchy

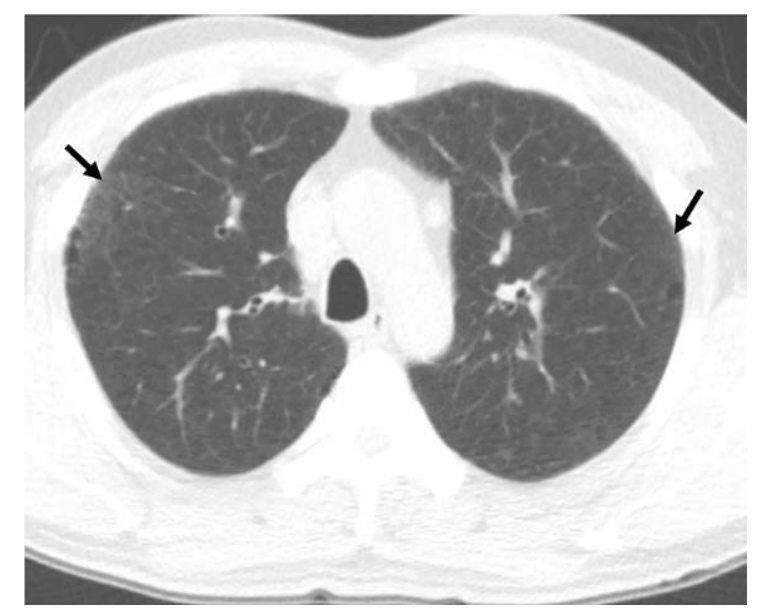

Figure I A 45-year-old male smoker with pathologically diagnosed RB. Notes: An axial CT image at the level of the aortic arch shows poorly defined bilateral centrilobular nodules (black arrows) reflecting the accumulation of smoker's macrophages. Image courtesy of Samsung Medical Center.

Abbreviations: $\mathrm{CT}$, computed tomography; RB, respiratory bronchiolitis.

GGOs, which are correlated with macrophage accumulation in the alveolar spaces, and mild interlobular septal thickening (Figure 1). ${ }^{3,17,22,24,25}$ Ancillary CT findings are bronchial wall thickening and emphysema due to cigarette smoking. ${ }^{17,22,24}$ The differential diagnoses of RB/RB-ILD include subacute hypersensitivity pneumonitis (HP), DIP and nonspecific interstitial pneumonia (NSIP). ${ }^{17}$ Because patients with HP are usually nonsmokers and cigarette smoke is considered to be protective against HP, a history of smoking or the presence of emphysema on CT is an important clue to help distinguish RB from HP. ${ }^{3,26} \mathrm{GGO}$ of RB/RB-ILD is less extensive and more poorly defined and tends to predominate in the upper lobes more frequently than that typically observed in DIP. ${ }^{17}$

\section{DIP}

DIP is exceedingly rare, and its true prevalence and incidence are unknown. ${ }^{27}$ This condition was first recognized by Liebow et $\mathrm{al}^{28}$ in 1965 and was described as histopathological findings of uniform air space filling by "large cells" that were interpreted as the accumulation of desquamated cells from the alveolar wall. ${ }^{29}$ However, this view has long been discarded and it is now recognized that these cells are macrophages. ${ }^{30,31}$ RB/RB-ILD and DIP are the abnormal accumulation of macrophages in the air spaces, and the key features that differentiate between the two are the distribution and extent of macrophage accumulation (Table 1). ${ }^{32}$ The hallmark histological feature of DIP is extensive, diffuse and uniform airspace filling by smoker's macrophages. ${ }^{29,30}$ The relationship between cigarette smoke and DIP has been proven, and $40 \%-90 \%$ of patients affected by DIP are smokers. ${ }^{4,33,34}$ However, DIP is not always associated with cigarette smoke and is 
Table I Summary of key features

\begin{tabular}{|c|c|c|}
\hline Characteristics & RB/RB-ILD & DIP \\
\hline Incidence according to sex & $M=F$ & $M>F$ \\
\hline \multirow[t]{2}{*}{ Clinical features } & Chronic cough & Chronic cough with bilateral crackles \\
\hline & Inspiratory crackles & Digital clubbing $(\sim 50 \%)$ \\
\hline \multirow[t]{2}{*}{ PFTs } & Normal or mixed restrictive-obstructive pattern & Restrictive pattern \\
\hline & Decreased DLco & Reduction in DLco \\
\hline \multirow[t]{2}{*}{ Bronchoalveolar lavage } & Increased macrophages & Increased macrophages \\
\hline & Modest increase in neutrophils & $\begin{array}{l}\text { Mild increase in the percentage of eosinophil and } \\
\text { neutrophil cells }\end{array}$ \\
\hline Key histopathological finding & Pigmented macrophages in the respiratory bronchioles & Diffuse and uniform, filled with pigmented macrophages \\
\hline \multirow[t]{3}{*}{ Radiological findings } & Centrilobular nodules and GGOs, predominantly & Diffuse GGOs, predominantly lower and subpleural \\
\hline & in the upper and middle lobes & \\
\hline & Mild interlobular septal thickening & \\
\hline Spontaneous improvement & Possible & Occasionally \\
\hline Treatment & Smoking cessation & Smoking cessation and steroid \\
\hline
\end{tabular}

Abbreviations: DIP, desquamative interstitial pneumonia; DLco, diffusing capacity of the lung for carbon monoxide; F, female; GGO, ground-glass opacity; ILD, interstitial lung disease; M, male; PFT, pulmonary function test; RB, respiratory bronchiolitis.

also reported to occur as a reactive phenomenon in a variety of other conditions, including drug reactions, leukemia, asbestosis, pneumoconiosis, and connective tissue diseases such as rheumatoid arthritis, lupus, and scleroderma. ${ }^{35-43}$ The average age at symptom onset is during the fourth and sixth decades, and patients present with slowly progressive breathlessness during exercise and a dry cough. ${ }^{4,29,39}$ PFTs reveal restrictive pattern with a decreased DLco. ${ }^{8}$
Chest radiographs are often normal or show GGO or a reticulonodular pattern in the lower zone, but these patterns are nonspecific for the detection of DIP. ${ }^{24,28,33,44} \mathrm{CT}$ finding mainly seen in DIP is diffuse GGOs with subpleural and lower zone predominance, which correlate histologically with the partial replacement of alveolar air by macrophages (Figure 2) ${ }^{4,29,45,46}$ Hartman et a ${ }^{45}$ reported that in 22 patients with biopsy-proven DIP, GGOs that involved the mid and
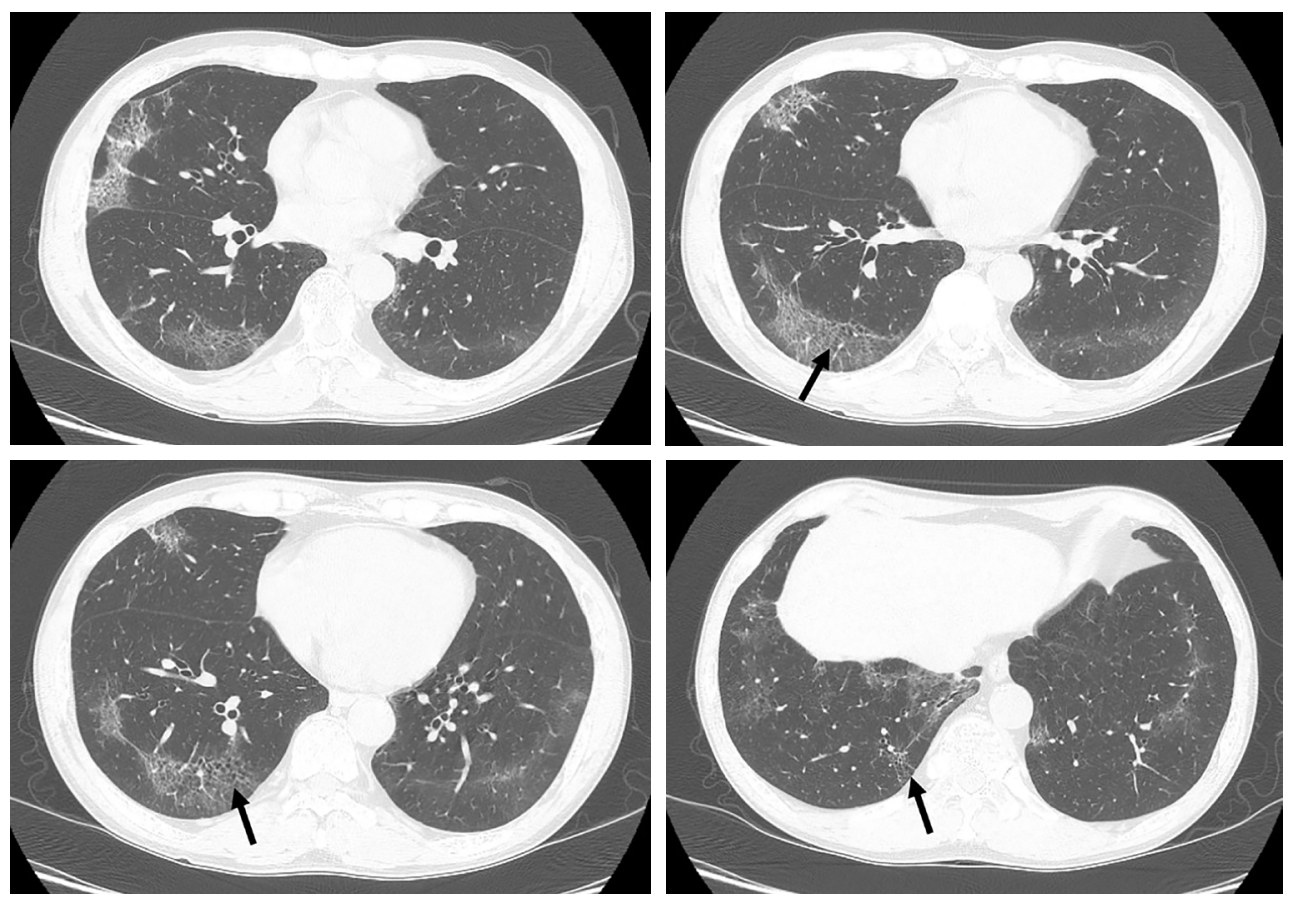

Figure 2 A 57-year-old male smoker with pathologically diagnosed DIP.

Notes: The axial CT image shows GGO in a subpleural and lower distribution. Thin-walled cysts (black arrows) are seen within the region of the GGOs. Image courtesy of Samsung Medical Center.

Abbreviations: CT, computed tomography; DIP, desquamative interstitial pneumonia; GGO, ground-glass opacity. 

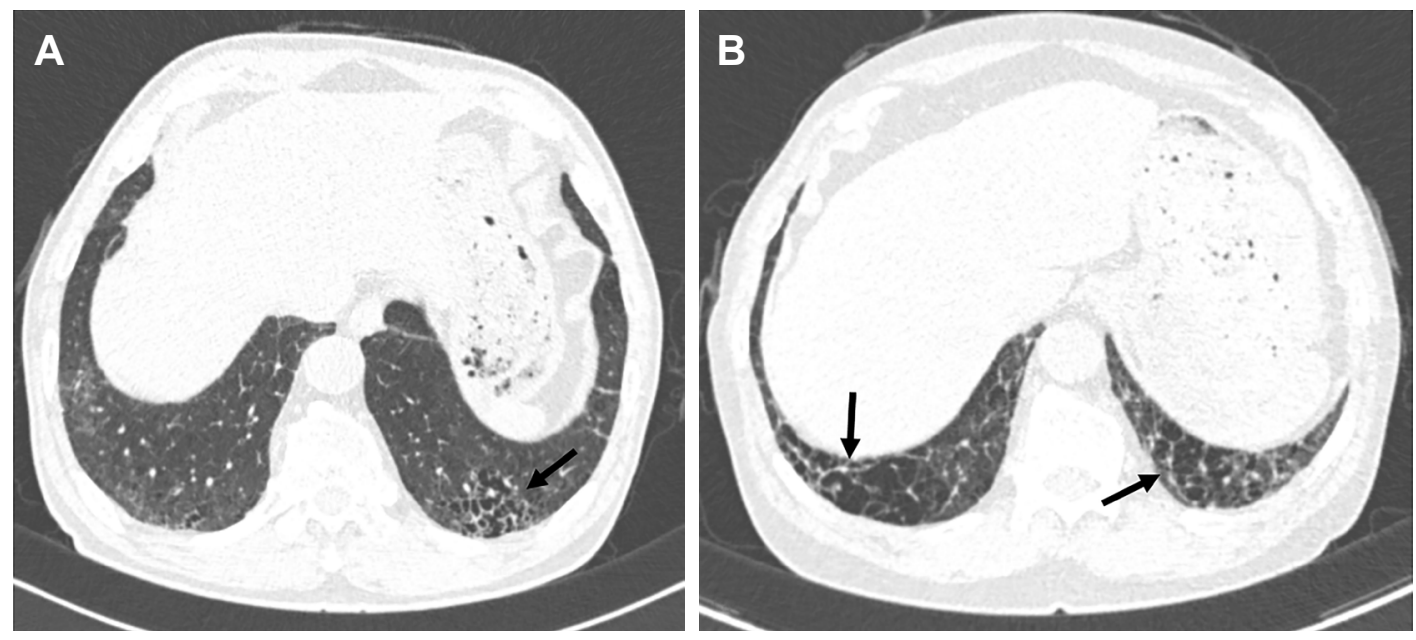

Figure 3 CT features of AEF.

Notes: (A) A 70-year-old male smoker (50 pack-years) showing up to $10 \mathrm{~mm}$ sized multiple thick-walled areas (black arrow) of centrilobular and paraseptal emphysema. (B) A 70-year-old male ex-smoker (72 pack-years) showing up to $25 \mathrm{~mm}$ sized multiple thick-walled area (black arrows) of centrilobular and paraseptal emphysema. Image courtesy of Samsung Medical Center.

Abbreviations: AEF, airspace enlargement with fibrosis; $\mathrm{CT}$, computed tomography.

lower zones were seen in all cases. Unlike other inhalational lung diseases, DIP tends to be predominant in the lower lung zone; the reason for this pathogenesis is unclear. ${ }^{3}$ Other findings in patients with DIP are irregular linear opacities, traction bronchiectasis, cystic spaces, and emphysema. ${ }^{45}$ Cystic spaces may be present in areas of GGOs, and the small cystic air spaces seen in DIP have been shown to be histologically correlated with dilated alveolar ducts and bronchiolectasis. ${ }^{47}$ It is important to recognize that the CT features of DIP are nonspecific. In one study, confident diagnoses by experienced thoracic radiologists were correct in $59 \%$ of cases of DIP. ${ }^{48}$ DIP differs from NSIP by its absence of fibrotic features, such as traction bronchiectasis and volume loss. ${ }^{17} \mathrm{~A}$ history of cigarette smoking and an increase in alveolar macrophages in bronchoalveolar lavage analysis may also be helpful in the diagnosis of DIP..$^{8,17}$ The ATS/ERS IIP statement mentioned that DIP and RB have to be distinguished from airspace enlargement with fibrosis (AEF). AEF is not regarded as distinct from IIP and is a smoking-related phenomenon., ${ }^{9,17}$ AEF demonstrates the presence of more interstitial fibrosis admixed with emphysema (Figure 3). 17,49,50

\section{Difficulties in establishing the diagnosis of smoking-related IIPs}

Pathologists may often encounter a mixture of histopathological patterns that will suggest more than one disease and therefore may find it difficult to make a single pathological diagnosis. ${ }^{31,32}$ Overlapping patterns of ILDs are not easily classified as a single disorder. ${ }^{51}$ Smokingrelated IIPs are good examples of ILD overlap. ${ }^{51} \mathrm{RB} / \mathrm{RB}-$ ILD may share some histopathological and radiological patterns with DIP. ${ }^{3,4,10}$ Although the distinction between $\mathrm{RB} / \mathrm{RB}-\mathrm{ILD}$ and DIP is determined by the distribution and extent of macrophage accumulation, this is subjective and may vary depending on the site of biopsy. ${ }^{3}$ Studies have shown that the histopathological pattern of RB/RB-ILD may overlap with the pattern of DIP. ${ }^{10,34}$ Despite histological overlap between RB/RB-ILD and DIP, the radiological manifestations of RB/RB-ILD and DIP are often different. ${ }^{3}$ Therefore, imaging distinctions can help to distinguish the two diseases. Key findings of RB/RB-ILD are poorly defined centrilobular nodules and patchy GGOs with an upper zone distribution, whereas in DIP, bilateral GGOs have a lower zone distribution; cystic lesions may be present in areas of GGO ${ }^{3,17}$ However, it is not surprising that imaging findings can overlap between $\mathrm{RB} / \mathrm{RB}-\mathrm{ILD}$ and DIP, and a prospective diagnosis can be difficult. ${ }^{3,4}$ A study evaluating the radiological pattern of 40 biopsy-proven RB, RB-ILD, or DIP patients described their radiological overlap; some overlap of radiological findings between RB/RB-ILD and DIP exists, and the radiological features of these disorders represent a different degree of severity of small airway and parenchymal reactions to cigarette smoke. ${ }^{46}$

The interrelationships between the various smokingrelated diffuse ILDs are now emerging. ${ }^{52}$ There are coexistent radiological-histopathological patterns, or one entity is 

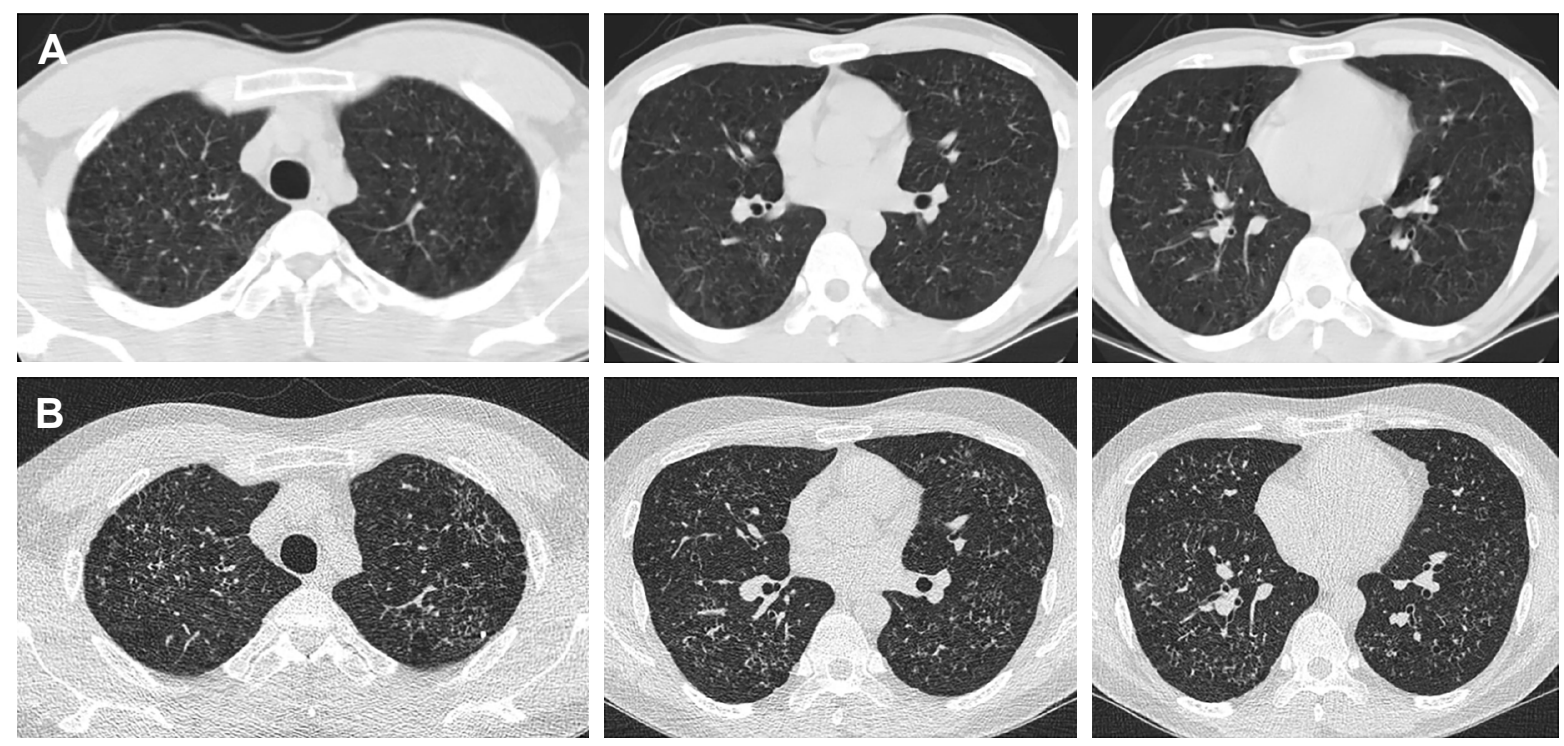

Figure 4 A 26-year-old male ex-smoker with pathologically diagnosed RB.

Notes: (A) Initial chest CT revealed bilateral and symmetric bizarre-shaped cysts and nodules with an upper zone predominant distribution and sparing of the costophrenic angles. (B) After 136 months, there was an increase in the extent of nodules in both lungs after the patient had resumed smoking. The lesions markedly decreased after smoking cessation on follow-up chest radiography. Image courtesy of Samsung Medical Center.

Abbreviations: CT, computed tomography; RB, respiratory bronchiolitis.

transformed into another apparently distinct entity. ${ }^{51} \mathrm{LCH}$ is an uncommon ILD that is characterized by the proliferation of Langerhans-type cells, and it occurs almost exclusively in smokers or ex-smokers. ${ }^{53,54}$ Because of the strong association with smoking, emphysema and RB-/DIP-like changes frequently coexist in patients with LCH (Figure 4); therefore, the radiological and histopathological differentiation of LCH from these disorders may be difficult. ${ }^{29,32}$ In one study, RB-/DIP-like changes were present in all biopsy specimens taken from 14 patients with $\mathrm{LCH}$, and they were correlated with cumulative exposure to cigarette smoke. ${ }^{55}$ Smoking-related IIPs are difficult to distinguish from other ILDs and sometimes co-occur. The coexistence of DIP and NSIP is frequent. ${ }^{8}$ Furthermore, $\sim 30 \%$ of patients with DIP are reported to be indistinguishable from NSIP. ${ }^{56}$ Given that fibrotic NSIP has a temporally uniform pattern of interstitial fibrosis, this result is similar to the findings of DIP histopathology in which the macrophages have been removed from the alveoli. ${ }^{57}$

In the diagnosis of smoking-related IIPs, the surgical or radiological finding may be evident, but the diagnosis may be difficult because of histological and radiological overlapping or coexistence of other ILDs. A representative area of the disease or a coexistent fibrotic process at the time of biopsy may not have been included in the biopsy. It is possible to diagnose correctly smokingrelated IIPs as comprehensively evaluating pathology, imaging, and clinical manifestations. Therefore, the role of multidisciplinary teams in the diagnosis of smoking-related IIPs is important.

\section{Natural history and longitudinal behavior of smoking-related IIPs}

There is a relative lack of large prospective studies describing radiological findings or longitudinal changes in cigarette smokers with biopsy-proven RB or DIP. ${ }^{17}$ Remy-Jardin et al ${ }^{58}$ reported that GGO, emphysema, and centrilobular nodules increased from $28 \%$ to $42 \%, 26 \%$ to $40 \%$, and $33 \%$ to $35 \%$, respectively, in current smokers during a mean follow-up period of 5.5 years. In a 3-year follow-up study, centrilobular nodules increased in $7.1 \%$ of patients with an RB pattern and were stable in $85.7 \% .{ }^{59}$ In another study, centrilobular nodules and GGO improved in all patients with biopsy-proven RB-ILD who quit smoking, and the reticular patterns, emphysema, and traction bronchiolectasis remained unchanged during the follow-up period. ${ }^{60} \mathrm{RB}$ can be found in ex-smokers many years after smoking cessation. ${ }^{11}$ In addition, some patients with RB-ILD remain unchanged or experience a deteriorated condition after smoking cessation and corticosteroid therapy. ${ }^{10,20,60}$ The degree of improvement in RB features on CT may depend on the duration of smoking cessation and the degree of inflammation and fibrosis. ${ }^{60}$ The extent of GGO and cystic lesions seen on CT in most patients with 
DIP remains unchanged or improves with corticosteroid therapy. ${ }^{47,61}$ In a long-term CT follow-up study of patients with DIP, an increase in the frequency of thin-walled cysts within the GGOs was observed, and the new appearance of honeycombing was noted in five of 14 patients. This study indicated that some patients with DIP may progress to fibrosis with honeycombing changes on $\mathrm{CT}$ despite a favorable response to corticosteroid therapy. ${ }^{62}$

$\mathrm{RB}$ is a very common finding in cigarette smokers, with a prevalence ranging from $57 \%$ to $100 \%{ }^{4,29}$ In current or ex-smokers, it is possible that RB can coexist with other ILDs (Figure 5). Initial radiological manifestations and longterm changes were heterogeneous, even when diagnosed pathologically as RB or DIP. A different study reported that fibrotic NSIP or usual interstitial pneumonia (UIP) patterns may be seen in patients with pathologically proven DIP on high-resolution CT several years after a biopsy has been carried out. ${ }^{63}$ In one case, a surgical lung biopsy revealed DIP and the histopathology at the time of lung transplantation revealed a pattern of NSIP. ${ }^{64}$ It is therefore possible that DIP may evolve to fibrotic NSIP or UIP. However, diagnosis of DIP at biopsy might have represented sampling error that areas with a coexistent fibrotic process at the time of biopsy may not have been included in the biopsy. ${ }^{63}$ Therefore, a longitudinal study with larger populations of patients with smoking-related IIPs is needed to confirm this. Although pathologically confirmed as smoking-related IIPs, radiological patterns of a variety of ILDs may also be seen by considering serial radiological examinations (Figure 6). Long-term follow-up of images is important because smoking-related IIPs may overlap and can coexist with other ILDs or there may be a sampling error at the time of biopsy.
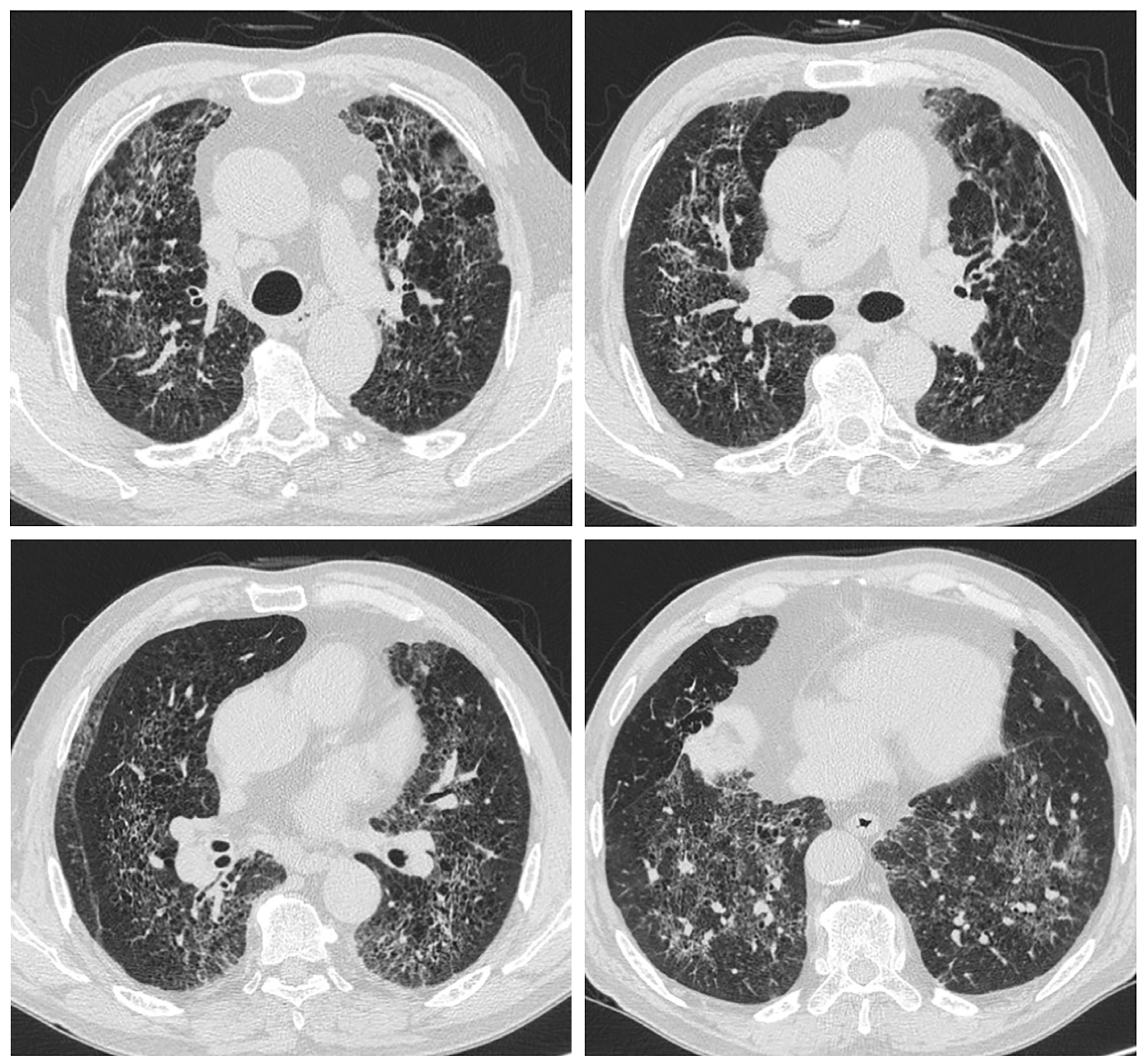

Figure 5 A 66-year-old male ex-smoker with lung biopsy-proven RB-ILD.

Notes: There were bronchiolocentric GGOs and traction bronchiectasis in both lungs that represented airway-centered interstitial fibrosis. Image courtesy of Samsung Medical Center.

Abbreviations: GGO, ground-glass opacity; ILD, interstitial lung disease; RB, respiratory bronchiolitis. 

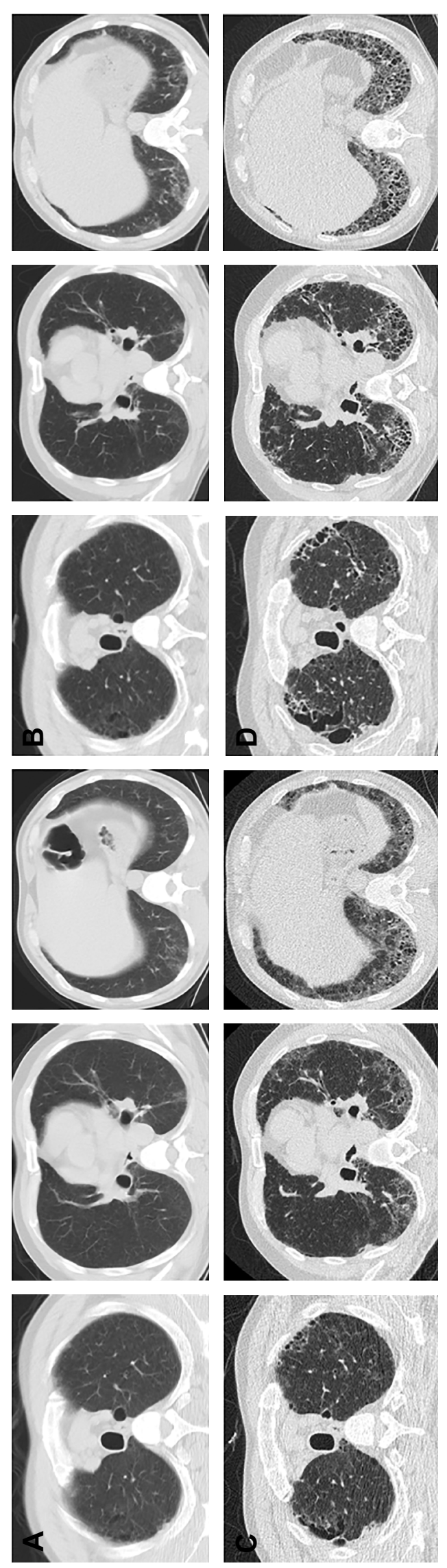

\section{Conclusion}

Histological, imaging, and clinical differentiation of smoking-related IIPs in smokers is not black and white. The histopathological differentiation of RB/DIP and other ILDs may be challenging. Initial radiological manifestations and long-term changes were heterogeneous, even when diagnosed as pathologically RB/RB-ILD or DIP. The mainstay of treatment in patients with RB/RB-ILD is smoking cessation, and treatment in patients with DIP consists of corticosteroid. In addition, clinical deterioration may be seen in two-third of patients with untreated DIP. DIP or RB/RB-ILD patients with coexistent UIP or NSIP may have a worse prognosis. Therefore, it is important to distinguish the smoking-related IIPs accurately. Since the overlap of features makes it impossible to assign a single specific diagnostic entity, a clinical-radiological-pathological discussion in smokers is important for making the diagnosis of smoking-related IIPs; long-term radiological evaluation is essential for monitoring morphological changes that may occur during follow-up in these patients.

\section{Acknowledgment}

The use of images was approved by the Institutional Review Board of Samsung Medical Center, and informed consent was waived.

\section{Author contributions}

All authors contributed toward data analysis, drafting and critically revising the paper, gave final approval of the version to be published, and agree to be accountable for all aspects of the work.

\section{Disclosure}

The authors report no conflicts of interest in this work.

\section{References}

1. Caminati A, Harari S. Smoking-related interstitial pneumonias and pulmonary Langerhans cell histiocytosis. Proc Am Thorac Soc. 2006; 3(4):299-306.

2. Talhout R, Schulz T, Florek E, van Benthem J, Wester P, Opperhuizen A. Hazardous compounds in tobacco smoke. Int $J$ Environ Res Public Health. 2011;8(2):613-628.

3. Kligerman S, Franks TJ, Galvin JR. Clinical-radiologic-pathologic correlation of smoking-related diffuse parenchymal lung disease. Radiol Clin North Am. 2016;54(6):1047-1063.

4. Madan R, Matalon S, Vivero M. Spectrum of smoking-related lung diseases: imaging review and update. $J$ Thorac Imaging. 2016;31(2):78-91.

5. Vassallo R, Ryu JH. Smoking-related interstitial lung diseases. Clin Chest Med. 2012;33(1):165-178.

6. Margaritopoulos GA, Vasarmidi E, Jacob J, Wells AU, Antoniou KM. Smoking and interstitial lung diseases. Eur Respir Rev. 2015;24(137): 428-435.

7. Neurohr C, Behr J. Changes in the current classification of IIP: a critical review. Respirology. 2015;20(5):699-704. 
8. Margaritopoulos GA, Harari S, Caminati A, Antoniou KM. Smokingrelated idiopathic interstitial pneumonia: a review. Respirology. 2016; 21(1):57-64.

9. Travis WD, Costabel U, Hansell DM, et al; ATS/ERS Committee on Idiopathic Interstitial Pneumonias. An official American Thoracic Society/European Respiratory Society statement: update of the international multidisciplinary classification of the idiopathic interstitial pneumonias. Am J Respir Crit Care Med. 2013;188(6):733-748.

10. Moon J, du Bois RM, Colby TV, Hansell DM, Nicholson AG. Clinical significance of respiratory bronchiolitis on open lung biopsy and its relationship to smoking related interstitial lung disease. Thorax. 1999; 54(11):1009-1014.

11. Fraig M, Shreesha U, Savici D, Katzenstein AL. Respiratory bronchiolitis: a clinicopathologic study in current smokers, ex-smokers, and never-smokers. Am J Surg Pathol. 2002;26(5):647-653.

12. Sieminska A, Kuziemski K. Respiratory bronchiolitis-interstitial lung disease. Orphanet J Rare Dis. 2014;9:106.

13. Niewoehner DE, Kleinerman J, Rice DB. Pathologic changes in the peripheral airways of young cigarette smokers. $N$ Engl J Med. 1974; 291(15):755-758.

14. Mehta H, Nazzal K, Sadikot RT. Cigarette smoking and innate immunity. Inflamm Res. 2008;57(11):497-503.

15. Wallace WA, Gillooly M, Lamb D. Intra-alveolar macrophage numbers in current smokers and non-smokers: a morphometric study of tissue sections. Thorax. 1992;47(6):437-440.

16. Rao RN, Goodman LR, Tomashefski JF Jr. Smoking-related interstitial lung disease. Ann Diagn Pathol. 2008;12(6):445-457.

17. Sverzellati N, Lynch DA, Hansell DM, Johkoh T, King TE Jr, Travis WD. American Thoracic Society-European Respiratory Society classification of the idiopathic interstitial pneumonias: advances in knowledge since 2002. Radiographics. 2015;35(7):1849-1871.

18. Myers JL, Veal CF Jr, Shin MS, Katzenstein AL. Respiratory bronchiolitis causing interstitial lung disease. A clinicopathologic study of six cases. Am Rev Respir Dis. 1987;135(4):880-884.

19. Portnoy J, Veraldi KL, Schwarz MI, et al. Respiratory bronchiolitisinterstitial lung disease: long-term outcome. Chest. 2007;131(3): 664-671.

20. Ryu JH, Myers JL, Capizzi SA, Douglas WW, Vassallo R, Decker PA. Desquamative interstitial pneumonia and respiratory bronchiolitisassociated interstitial lung disease. Chest. 2005;127(1):178-184.

21. Davies G, Wells AU, du Bois RM. Respiratory bronchiolitis associated with interstitial lung disease and desquamative interstitial pneumonia. Clin Chest Med. 2004;25(4):717-726, vi.

22. Park JS, Brown KK, Tuder RM, Hale VA, King TE Jr, Lynch DA. Respiratory bronchiolitis-associated interstitial lung disease: radiologic features with clinical and pathologic correlation. J Comput Assist Tomogr. 2002;26(1):13-20.

23. Attili AK, Kazerooni EA, Gross BH, Flaherty KR, Myers JL, Martinez FJ. Smoking-related interstitial lung disease: radiologicclinical-pathologic correlation. Radiographics. 2008;28(5):1383-1396. discussion 1396-1388.

24. Palmucci S, Roccasalva F, Puglisi S, et al. Clinical and radiological features of idiopathic interstitial pneumonias (IIPs): a pictorial review. Insights Imaging. 2014;5(3):347-364.

25. Remy-Jardin M, Remy J, Gosselin B, Becette V, Edme JL. Lung parenchymal changes secondary to cigarette smoking: pathologic-CT correlations. Radiology. 1993;186(3):643-651.

26. Lacasse Y, Selman M, Costabel U, et al; HP Study Group. Clinical diagnosis of hypersensitivity pneumonitis. Am J Respir Crit Care Med. 2003; 168(8):952-958.

27. Vassallo R. Diffuse lung diseases in cigarette smokers. Semin Respir Crit Care Med. 2012;33(5):533-542.

28. Liebow AA, Steer A, Billingsley JG. Desquamative interstitial pneumonia. Am J Med. 1965;39:369-404.

29. Marten K, Hansell DM. Imaging of macrophage-related lung diseases. Eur Radiol. 2005;15(4):727-741.

30. Farr GH, Harley RA, Hennigar GR. Desquamative interstitial pneumonia. An electron microscopic study. Am J Pathol. 1970;60(3):347-370.
31. Walsh SL, Nair A, Desai SR. Interstitial lung disease related to smoking: imaging considerations. Curr Opin Pulm Med. 2015;21(4):407-416.

32. Desai SR, Ryan SM, Colby TV. Smoking-related interstitial lung diseases: histopathological and imaging perspectives. Clin Radiol. 2003;58(4):259-268.

33. Carrington CB, Gaensler EA, Coutu RE, FitzGerald MX, Gupta RG. Natural history and treated course of usual and desquamative interstitial pneumonia. N Engl J Med. 1978;298(15):801-809.

34. Yousem SA, Colby TV, Gaensler EA. Respiratory bronchiolitisassociated interstitial lung disease and its relationship to desquamative interstitial pneumonia. Mayo Clin Proc. 1989;64(11):1373-1380.

35. Abraham JL, Hertzberg MA. Inorganic particulates associated with desquamative interstitial pneumonia. Chest. 1981;80(1 suppl):67-70.

36. Bone RC, Wolfe J, Sobonya RE, et al. Desquamative interstitial pneumonia following chronic nitrofurantoin therapy. Chest. 1976;69(2 suppl): 296-297.

37. Corrin B, Price AB. Electron microscopic studies in desquamative interstitial pneumonia associated with asbestos. Thorax. 1972;27(3): 324-331.

38. Esmaeilbeigi F, Juvet S, Hwang D, Mittoo S. Desquamative interstitial pneumonitis in a patient with systemic lupus erythematosus. Can Respir J. 2012;19(1):50-52.

39. GodbertB, WisslerMP, Vignaud JM. Desquamative interstitial pneumonia: an analytic review with an emphasis on aetiology. Eur Respir Rev. 2013;22(128):117-123.

40. Goldstein JD, Godleski JJ, Herman PG. Desquamative interstitial pneumonitis associated with monomyelocytic leukemia. Chest. 1982;81(3): 321-325.

41. Ishii H, Iwata A, Sakamoto N, Mizunoe S, Mukae H, Kadota J. Desquamative interstitial pneumonia (DIP) in a patient with rheumatoid arthritis: is DIP associated with autoimmune disorders? Intern Med. 2009;48(10):827-830.

42. Lougheed MD, Roos JO, Waddell WR, Munt PW. Desquamative interstitial pneumonitis and diffuse alveolar damage in textile workers. Potential role of mycotoxins. Chest. 1995;108(5):1196-1200.

43. Swartz JS, Chatterjee S, Parambil JG. Desquamative interstitial pneumonia as the initial manifestation of systemic sclerosis. J Clin Rheumatol. 2010;16(6):284-286.

44. Patchefsky AS, Israel HL, Hoch WS, Gordon G. Desquamative interstitial pneumonia: relationship to interstitial fibrosis. Thorax. 1973;28(6): 680-693.

45. Hartman TE, Primack SL, Swensen SJ, Hansell D, McGuinness G, Muller NL. Desquamative interstitial pneumonia: thin-section CT findings in 22 patients. Radiology. 1993;187(3):787-790.

46. Heyneman LE, Ward S, Lynch DA, Remy-Jardin M, Johkoh T, Muller NL. Respiratory bronchiolitis, respiratory bronchiolitis-associated interstitial lung disease, and desquamative interstitial pneumonia: different entities or part of the spectrum of the same disease process? AJR Am J Roentgenol. 1999;173(6):1617-1622.

47. Akira M, Yamamoto S, Hara H, Sakatani M, Ueda E. Serial computed tomographic evaluation in desquamative interstitial pneumonia. Thorax. 1997;52(4):333-337.

48. Johkoh T, Muller NL, Cartier Y, et al. Idiopathic interstitial pneumonias: diagnostic accuracy of thin-section CT in 129 patients. Radiology. 1999; 211(2):555-560.

49. Katzenstein AL, Mukhopadhyay S, Zanardi C, Dexter E. Clinically occult interstitial fibrosis in smokers: classification and significance of a surprisingly common finding in lobectomy specimens. Hum Pathol. 2010;41(3):316-325.

50. Kawabata Y, Hoshi E, Murai K, et al. Smoking-related changes in the background lung of specimens resected for lung cancer: a semiquantitative study with correlation to postoperative course. Histopathology. 2008; 53(6):707-714.

51. Walsh SL, Hansell DM. Diffuse interstitial lung disease: overlaps and uncertainties. Eur Radiol. 2010;20(8):1859-1867.

52. Wells AU, Nicholson AG, Hansell DM. Challenges in pulmonary fibrosis. 4: smoking-induced diffuse interstitial lung diseases. Thorax. 2007;62(10):904-910. 
53. Harmon CM, Brown N. Langerhans cell histiocytosis: a clinicopathologic review and molecular pathogenetic update. Arch Pathol Lab Med. 2015;139(10):1211-1214.

54. Roden AC, Yi ES. Pulmonary Langerhans cell histiocytosis: an update from the pathologists' perspective. Arch Pathol Lab Med. 2016;140(3): 230-240.

55. Vassallo R, Jensen EA, Colby TV, et al. The overlap between respiratory bronchiolitis and desquamative interstitial pneumonia in pulmonary Langerhans cell histiocytosis: high-resolution CT, histologic, and functional correlations. Chest. 2003;124(4):1199-1205.

56. Sawata T, Bando M, Nakayama M, Mato N, Yamasawa H, Sugiyama Y. Influence of smoking in interstitial pneumonia presenting with a nonspecific interstitial pneumonia pattern. Intern Med. 2016;55(20): 2939-2944.

57. Hansell DM, Nicholson AG. Smoking-related diffuse parenchymal lung disease: HRCT-pathologic correlation. Semin Respir Crit Care Med. 2003;24(4):377-392.

58. Remy-Jardin M, Edme JL, Boulenguez C, Remy J, Mastora I, Sobaszek A. Longitudinal follow-up study of smoker's lung with thinsection CT in correlation with pulmonary function tests. Radiology. 2002;222(1):261-270.
59. Sverzellati N, Guerci L, Randi G, et al. Interstitial lung diseases in a lung cancer screening trial. Eur Respir J. 2011;38(2):392-400.

60. Nakanishi M, Demura Y, Mizuno S, et al. Changes in HRCT findings in patients with respiratory bronchiolitis-associated interstitial lung disease after smoking cessation. Eur Respir J. 2007;29(3):453-461.

61. Hartman TE, Primack SL, Kang EY, et al. Disease progression in usual interstitial pneumonia compared with desquamative interstitial pneumonia. Assessment with serial CT. Chest. 1996;110(2):378-382.

62. Kawabata Y, Takemura T, Hebisawa A, et al; Desquamative Interstitial Pneumonia Study Group. Desquamative interstitial pneumonia may progress to lung fibrosis as characterized radiologically. Respirology. 2012;17(8):1214-1221.

63. Craig PJ, Wells AU, Doffman S, et al. Desquamative interstitial pneumonia, respiratory bronchiolitis and their relationship to smoking. Histopathology. 2004;45(3):275-282.

64. Tazelaar HD, Wright JL, Churg A. Desquamative interstitial pneumonia. Histopathology. 2011;58(4):509-516.
International Journal of COPD

\section{Publish your work in this journal}

The International Journal of COPD is an international, peer-reviewed journal of therapeutics and pharmacology focusing on concise rapid reporting of clinical studies and reviews in COPD. Special focus is given to the pathophysiological processes underlying the disease, intervention programs, patient focused education, and self management protocols.

\section{Dovepress}

This journal is indexed on PubMed Central, MedLine and CAS. The manuscript management system is completely online and includes a very quick and fair peer-review system, which is all easy to use. Visit http://www.dovepress.com/testimonials.php to read real quotes from published authors.

Submit your manuscript here: http://www.dovepress.com/international-journal-of-chronic-obstructive-pulmonary-disease-journal 